\title{
The Importance of TEE when Suspected with Acute Pulmonary Embolism During Femur Fracture Surgery: A Case Report
}

\author{
Da Li MD, Yanqiu Ai. MD
}

Department of Anesthesiology, The First Affiliated Hospital of Zhengzhou University

\begin{abstract}
The diagnosis of pulmonary embolism is not easy in perioperative period due to many co-founding factors. Here, we report a case with a massive intraoperative pulmonary embolism that was identified with the aid of transesophageal echocardiography with subsequent pulmonary thromboembolectomy. This case report highlights the importance of use transesophageal echocardiography in the intraoperative period when a pulmonary embolism is suspected.
\end{abstract}

Key words: pulmonary embolism, transesophageal echocardiography, perioperative

\section{Introduction}

Intra-operative formation of a thrombus in the heart during femur surgery is not uncommon and could have no significant clinical consequence if the thrombus is small. However, the consequence of massive pulmonary embolism (PE) can be fatal. In this article, we discuss a case that demonstrates the importance of transthoracic echocardiography in hemodynamic disturbances.

\section{Case Description}

The examption of Internal Review Board was obained from the First Affiliated Hospital of Zhengzhou University. A 72-year-old woman underwent an elective open reduction and internal fixation for a distal femoral fracture. She had a history of hypertension and atrial fibrillation in 2007, and ECG prompt $\mathrm{T}$ wave change. Chest X-ray showed aortic tortuosity and enlargement of the cardiac image. Cardiac color Doppler imaging showed a little of mitral and aortic regurgitation, a decrease in left ventricular diastolic function, and ejection fraction of $56 \%$. Lung function test was normal. Femoral X-ray demonstrated right distal femur fracture. She regularly used aspirin and metoprolol to control blood pressure and heart rate. The New York Heart Association (NYHA) heart functional classification was III.

The patient entered the operating room and her ECG was monitored regularly. The induction of anesthesia was smooth. When the surgical team was manipulating the fracture, her blood pressure (BP) suddenly decreased to $63 / 43 \mathrm{mmHg}$, heart rate increased to 112 beats $/ \mathrm{min}$, and the saturation of pulse oxygen $\left(\mathrm{SpO}_{2}\right)$ fell to $72 \%$. $1 \mathrm{mg}$ methoxamine was used to raise the blood pressure without success. $2 \mathrm{mg}$ methoxamine, $6 \mathrm{mg}$ ephedrine, and $8 \mu \mathrm{g}$ nonadrenaline were subsequently given without significant blood pressure change. The central venous pressure was $15 \mathrm{mmHg}$. In addition, the end tidal carbon dioxide decreased to $10 \mathrm{mmHg}$. There were no significant airway pressure changes. While an allergic reaction was initially suspected, no dermatological changes were identified. Emergency blood gas indicated a partial pressure of artery carbon dioxide $\left(\mathrm{PaCO}_{2}\right)$ of $77.9 \mathrm{mmHg}$, and an oxygen partial pressure of $67 \mathrm{mmHg}$. Potential pulmonary embolism was suspected. A transesophageal echocardiography (TEE) was followed. It revealed an enlarged right atrium (Figure1), hypokinesia of the free right ventricle wall, and poor filling of left ventricular. The ratio of left/right ventricular apparent disorder and the pressure of tricuspid valve was $51 \mathrm{mmHg}$ with massive regurgitation of $3.57 \mathrm{~m} / \mathrm{s}$ (Figure 2). Severe tricuspid reflux was also observed (Figure 3). Epinephrine and milrinone

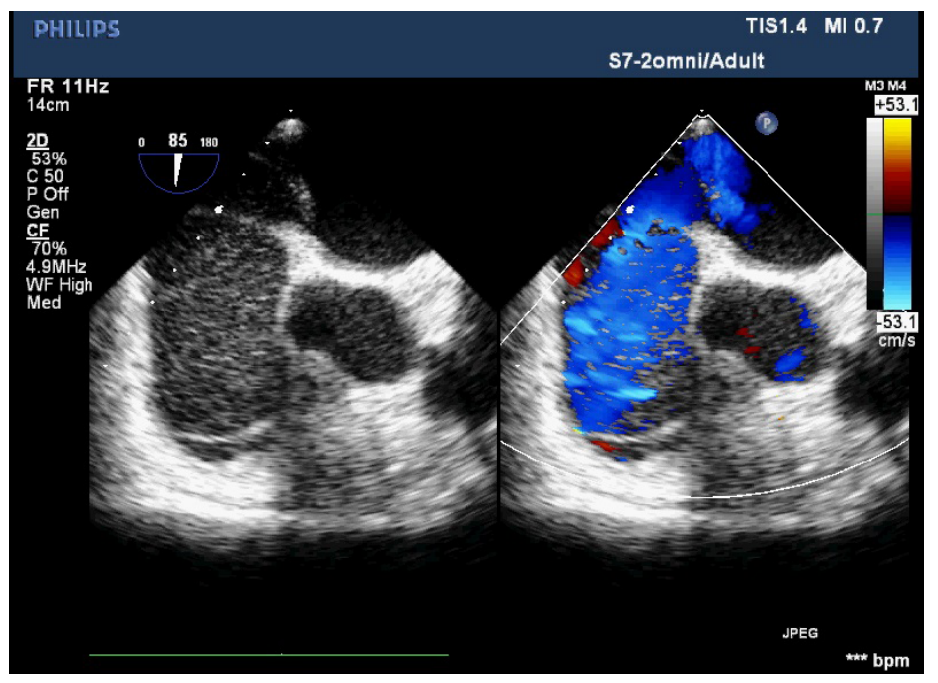

Figure 1. Right atrial on 2D-transesophageal echocardiography. Enlarged RA and hypokinesia of the free right ventricle wall were observed. 


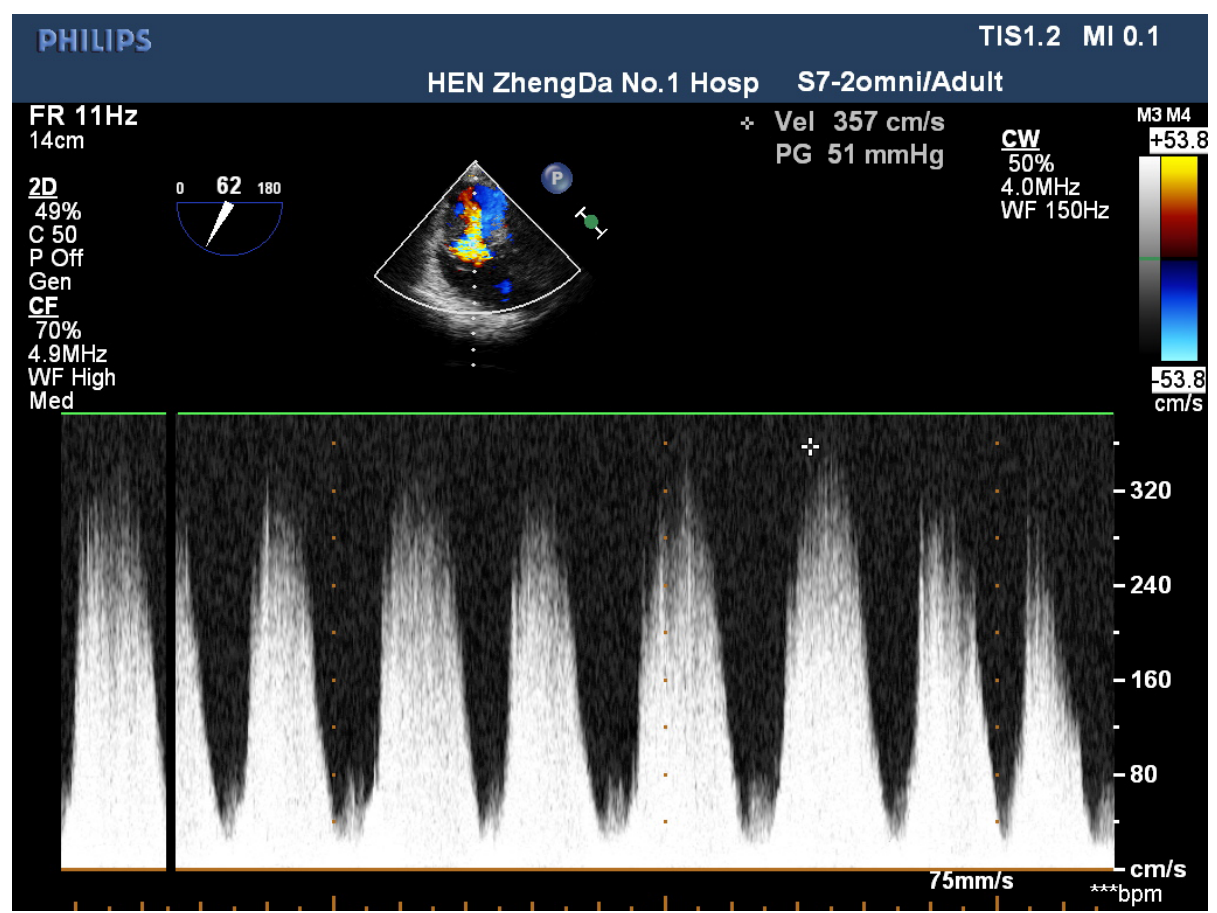

Figure 2. An imaging of a 2D-transesophageal echocardiography shows tricuspid valve regurgitation with the speed of $3.57 \mathrm{~m} / \mathrm{s}$ and Tricuspid valve pressure of $51 \mathrm{mmHg}$.

along with high-dose vasopressin were initiated. While no thrombi in the pulmonary or right ventricle were identified, unstable hemodynamics, changes in carbon dioxide, findings in TEE strongly suggested a possible major PE. Extracorporeal membrane oxygenation (ECMO) was immediately established and an emergent pulmonary thromboembolectomy was successfully performed. The patient was transferred to the surgical intensive care unit for monitoring and evaluation. The patient was discharged without residual deficits after 20 days in surgical intensive care unit.

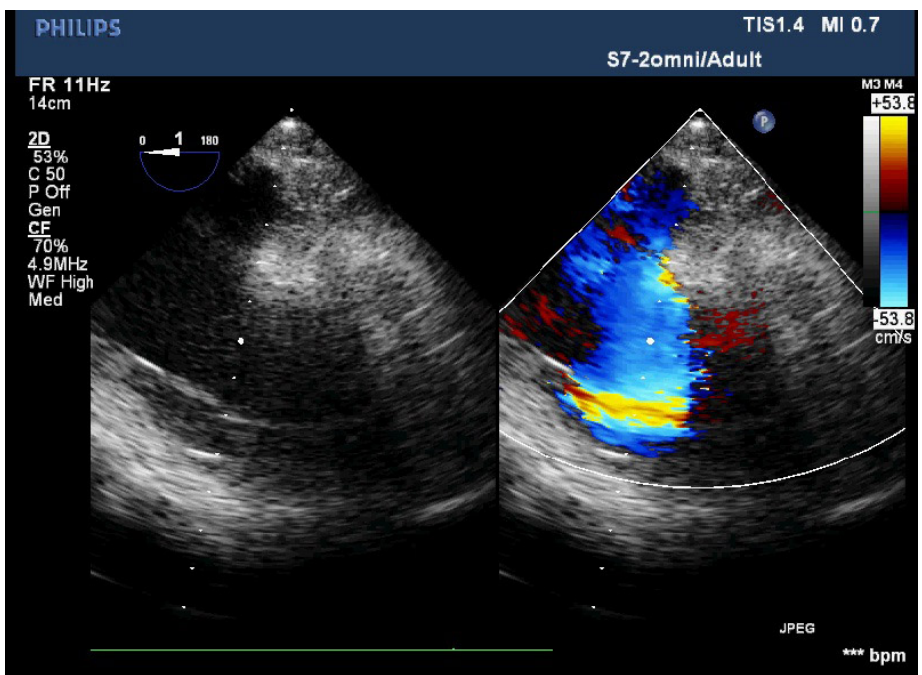

Figure 2. Tricuspid valve regurgitation on 2D-transesophageal echovardiography. Severe beam of tricuspid valve regurgitation was observed.
In this case report, we showed the utility of intraoperative TEE to diagnose severe PE.

\section{Discussion}

PE can occur in a variety of surgeries during the perioperative period, and its frequency can be associated significantly with mortality and morbidity. Timely diagnosis of pulmonary embolism is crucial to the prognosis of disease. Since patient is generally intubated under general anesthesia, TEE is suitable to be used to diagnose perioperative $\mathrm{PE} .^{[1,2]}$

Once PE occurs, acute changes in arterial alveolar carbon dioxide tension may be helpful to diagnose PE, common vital signs such as oxygen desaturation or hypotension may help too, but they are not specific for confirming PE. The perioperative use of TEE has been advised by the American Society of Ecocardiography ${ }^{[3]}$ to diagnose and treat patients with refractory hemodynamic instability ${ }^{[4]}$ and correctly manage the patient in life-threatening intraoperative hemodynamic disturbances without a diagnosis of PE. An embolus in the right heart was only observed in $4-18 \%$ of patients with pulmonary embolism. ${ }^{[5,6,7]}$ When we diagnose $\mathrm{PE}$ in the absence of direct visualization, echocardiographic evidence of pulmonary arterial obstruction may support. A secondary echocardiographic sign is right ventricular (RV) dysfunction and pulmonary hypertension. RV dysfunction exhibits RV regional wall motion abnormality and severe RV free-wall hypokinesis, known as the "Mcconnell sign" ${ }^{[8]}$, which was seen in this presentation. 
In conclusion, TEE is a suitable and alternative diagnostic tool for patients with unexplained shock and a suspected PE. Intraoperative TEE should be more important as a monitoring tool for PE-induced hemodynamic disturbances.

\section{Disclosure of Funding: None}

Conflict Interests Disclosure: The authors have no conflicting interests to disclose.

Corresponding Author: Corresponding author: Yanqiu Ai, MD. Department of Anesthesiology, The First Affiliated Hospital of Zhengzhou University, Zhengzhou, China. Email:aiyanqiu82@163.com

Editor: Renyu Liu, MD; PhD. Associate Professor, Department of Anesthesiology and Critical Care; Perelman School of Medicine at the University of Pennsylvania, 336 John Morgan building, 3620 Hamilton Walk, Philadelphia, PA 19104.Phone: 2157461485; FAX: 2153495078.1iur@ uphs.upenn.edu

\section{Additional publication details}

Journal short name: Transl Perioper \& Pain Med

Received Date: Dec 15, 2016

Accepted Date: Feb 28, 2017

Published Date: March 3, 2017

Transl Perioper \& Pain Med 2017; 2(2):3-5

\section{Citation and Copyright}

Citation: Li D, Ai Y. The Importance of TEE when Suspected with Acute Pulmonary Embolism During Femur Fracture Surgery: A Case Report. Transl Perioper \& Pain Med 2017; 2(2): 3-5

Copyright: (C) 2017 Li D, Ai Y. This is an open-access article distributed under the terms of the Creative Commons Attribution License, which permits unrestricted use, distribution, and reproduction in any medium, provided the original author and source are credited.

\section{References}

1. Vieillard-Baron A, Qanadli SD, Antakly Y, Fourme T, Loubieres Y. Transesopha-geal echocardiography for the diagnosis of pulmonary embolism with acute cor pulmonale: a comparison with radiological procedures.
Intensive Care Med 1998;24:429-33.PMID:9660256

2. van der Wouw PA, Koster RW, Delemarre BJ, de Vos R, Lampe-Schoenmaeckers AJ. Diagnostic accuracy of transesophageal echocardiographyduring cardiopulmonary resuscitation. J Am Coll Cardiol 1997; 30:780-3.PMID:9283540

3. Practice guidelines for perioperative transesophageal echocardiography: a report by the American Society of Anesthesiologists and the Society of Cardiovascular Anesthesiologists Task Force on transesophageal echocardiography. Anesthesiology 1996; 84:986-1006. PMID:8638856

4. Shillcut SK, Markin NW, Montzingo CR, Brakke TR. Use of Rapid Rescue perioperative Echocardiography to improve outcomes after hemodynamic instability in noncardiac surgical patients. J Cardiothorac Vasc Anesth, 2012;26:362-370.PMID:22226417

5. Goldhaber SZ, Visani L, De Rosa M. Acute pulmonary embolism: clinical outcomes in the International Cooperative Pulmonary Embolism Registry (ICOPER). Lancet, 1999; 353: 1386-89.PMID:10227218

6. Chartier L, Béra J, Delomez M, Asseman P, Beregi JP. Free-floating thrombi in the right heart: diagnosis, management, and prognostic indexes in 38 consecutive patients. Circulation, 1999; 99: 2779-83. PMID:10351972

7. Torbicki A, Galié N, Covezzoli A, Rossie E, De Rosa M. Right heart thrombi in pulmonary embolism: results from the International Cooperative Pulmonary Embolism Registry. J Am Coll Cardiol, 2003; 41: 2245-51.PMID:12821255

8. McConnell MV, Solomon SD, Rayan ME, Come PC, Goldhaber SZ. Regional right ventricular dysfunction detected by echocardiography in acute pulmonary embolism. Am J Cardiol 1996; 78: 469-73. PMID:8752195 